Kyryl Podostroiets

\title{
MATHEMATICAL MODEL OF THE METHOD OF TRACEABILITY THE METER UNIT FROM THE ETALON TO WORKING INSTRUMENTS IN LABORATORY CONDITIONS
}

The features of the process of metrological control of EDM instruments of measuring equipment are considered and known variants for its simplification are presented. As an example, we consider a method of traceability the meter unit from the etalon to working instruments in laboratory conditions by measuring zigzag distances. The mathematical model of the method of traceability the meter unit from the standard to working instruments in laboratory conditions is presented.

Keywords: etalon, EDM measuring instruments, calibration.

\section{УДК 666:691.32}

\section{И. П. Солоненко, к.т.н.}

Одесская государственная академия строительства и архитектуры, Одесса

\section{ПРИМЕНЕНИЕ СВЧ ИЗЛУЧАТЕЛЕЙ ДЛЯ ОПРЕДЕЛЕНИЯ СОДЕРЖАНИЯ ВЛАГИ В ОБРАЗЦАХ СТРОИТЕЛЬНЫХ МАТЕРИАЛОВ}

В статье рассматриваются существуюшие методы определения содержания влаги в строительных материалах. Приводятся результаты их анализа и сравнения. Предложен метод определения количества воды находящейся в строительных материалах путем воздействия на них сверхвысокочастотного излучения фиксированной мощности и времени воздействия. Приведена методика его применения в инженерной и технологической практике.

Ключевые слова: влажность, строительные материаль, СВЧ, песок, измерение, образец.

\section{Постановка проблемы}

Одним из направлений улучшения характеристик строительных материалов является повышение точности дозировки исходных компонентов. Чаще всего строительные материалы являются гидрофобными. Это требует применения эффективных методов для определения количества воды в материале. Кроме того, повышение качества строительных изделий также может быть достигнуто за счет точного определения содержания воды в их компонентах. Контроль влажности позволяет точно определить необходимое количество исходных материалов (песка, щебня, добавок, наполнителей и воды).

\section{Анализ литературы}

Анализ материалов исследований и публикаций [1 - 3] показывает, что в настоящее время используются такие методы определения влажности материалов: печах;

- определения влажности в лабораторных

- оценка влажности при помощи внешних источников тепла;

- тестирования влажности различными химическими и электрическими приборами.
Рассмотрим их:

1. Метод определения влажности с помощью карбида кальция в приборе ВП-2 (рис. 1) [2].

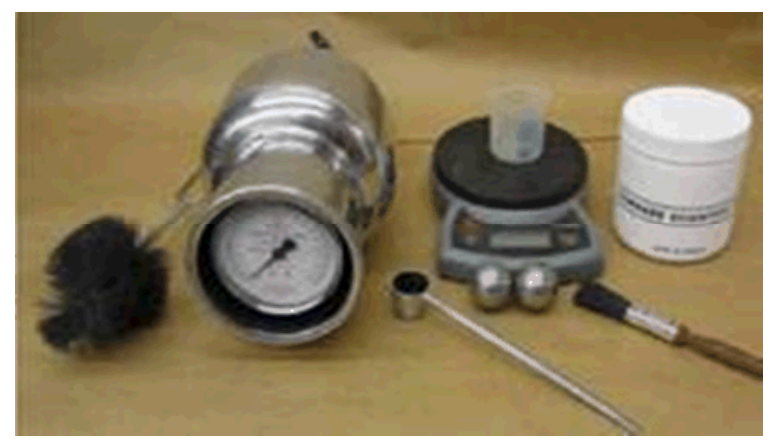

Рисунок 1 - Прибор ВП-2

2. Определение влажности по таблицам (таблица 1) [1].

Определение количества воды в материале, используя методы сравнения масс проб образцов (до и после высушивания).

Эти методы требуют значительных затрат времени для определения количества воды. 
Одеська державна академія технічного регулювання та якості

Таблица 1 - Ориентировочные значения влажности фракций размером более 10 мм

\begin{tabular}{|l|c|c|c|c|c|c|c|c|}
\hline \multirow{2}{*}{ Материал } & \multicolumn{9}{|l}{ Ориентировочное значение влажно- } \\
сти, \% по весу, при содержании \\
фракций крупнее 10 мм, доли еди- \\
ницы
\end{tabular}

3. Метод определения влажности материала (фракции меньше 10 мм) путем высушивания пробы (100 ... 200 г) с использованием горения денатурата в фарфоровой чашке диаметром $d=10 \ldots 12$ cм.

4. Определение влажности с использованием газовых горелок (рис. 2).

5. Метод определения влажности материала путем сравнения массы образца до и после высушивания в муфельной печи (рис. 3).

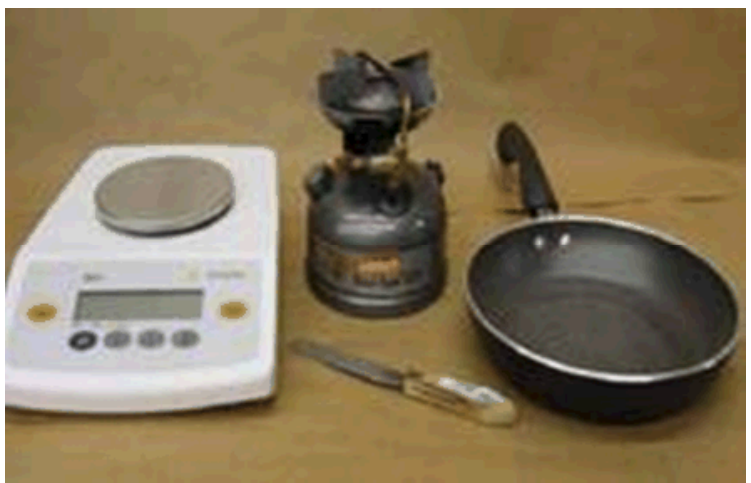

Рисунок 2 - Приборы для определения влажности

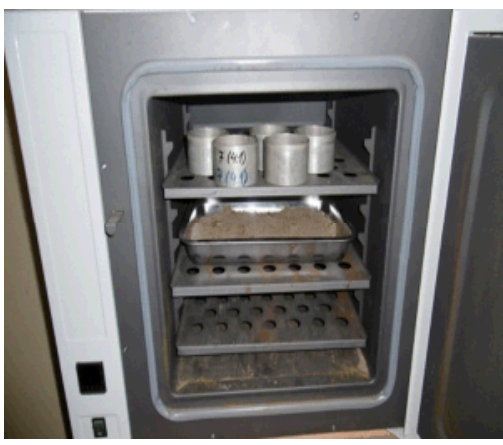

a)

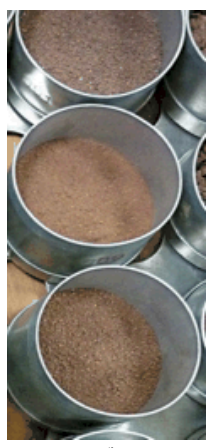

б)
Рисунок 3 - Определение влажности:

а) высушивание в муфельной печи проб песка; б) образцы материала
6. Метод определения влажности в зависимости от давления пара в образце исследуемого материала в СВЧ печи, предложенный Максимовым Г. А. (рис. 4) [3].

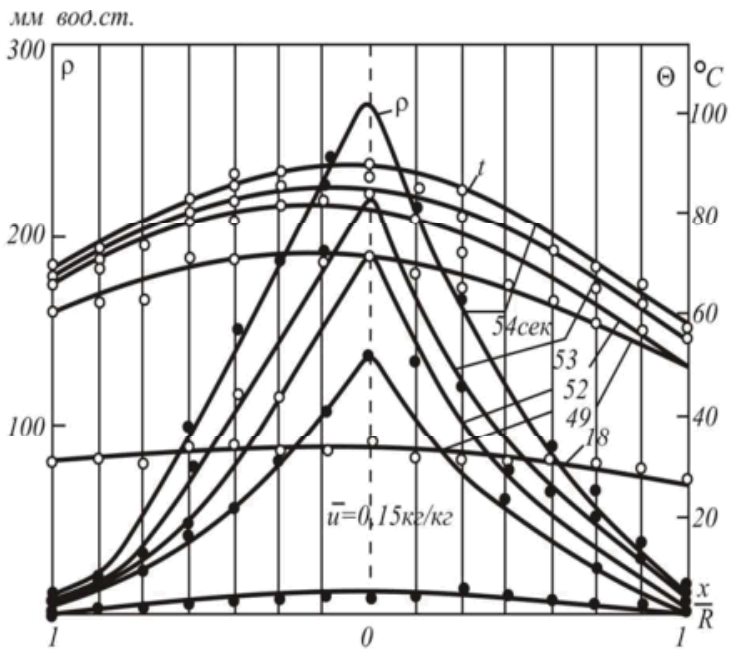

Рисунок 4 - Изменения температуры нагрева песка и давления пара при СВЧ нагреве (по данным Максимова Г.А.)

Опыты показали, что после начального периода нагрева распределение температуры внутри тела стабилизируется и в дальнейшем не меняется.

7. В странах ЕС согласно ASTM d4643-08 «Standard Test Method for Determination of Water (Moisture) Content of Soil by Microwave Oven Heating» [5] определение влажности грунтов производится с помощью сверхвысокочастотного излучения, которое применяется для полного высушивания образцов (рис. 5). Это позволяет ускорить выполнение работ в 40 раз $[6,7,8]$.

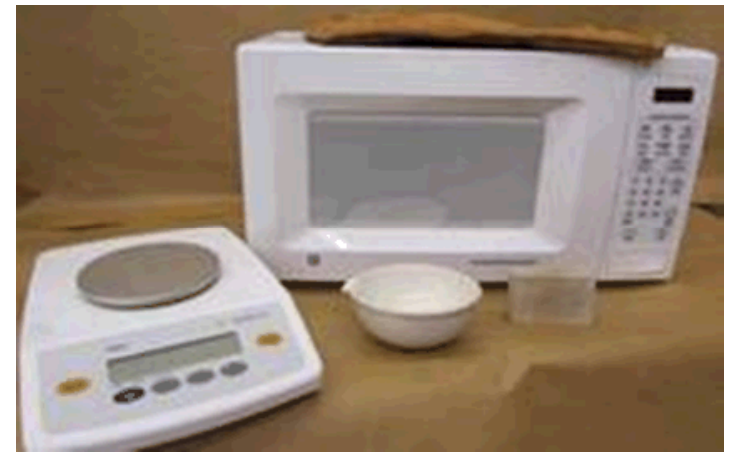

Рисунок 5 - СВЧ прибор, электронные весы, фарфоровая чаша

Следовательно, развитие методов определения влажности материалов может быть достигнута за счет принятой гипотезы: определение влажности строительного материала может быть 
получено в зависимости от величины его нагрева СВЧ излучением, при постоянных значениях времени и мощности излучения.

Цель работы: разработать метод определения влажности строительного материала по степени его нагрева.

Поставленная цель достигается решением следующих задач:

- теоретически обосновать степень нагрева строительного материала в зависимости от содержания воды в нем;

- провести лабораторные исследования влияния СВЧ излучения на нагрев строительного материала (песка) в зависимости от количества воды в нем;

- разработать метод определения влажности материала по величине его нагрева;

- разработать рекомендации по применению предложенного метода в инженерной практике.

\section{Решение проблемы}

Исходя из цели работы, разработан метод определения количества воды, находящейся в материале по температуре его нагрева СВЧ излучателем.

Суть метода состоит в том, что вода, которая находится в материале, при частоте $\mathrm{f}_{\text {рез }}=11700$ МГц попадает в зону резонанса, при котором наблюдается значительное поглощение энергии излучения. При этом сам материал, подвергающийся исследованию, практически не нагревается. Это позволяет получить зависимость температуры нагрева образца от количества воды в нем.

Поглощаемая водой энергия $(P)$ в объеме материала может быть рассчитана по формуле [9]:

$$
P=5,55 \times 10^{-11} \times \varepsilon \times \operatorname{tg} \delta \times E_{M}^{2} \times f \times V,
$$

где $V$ - суммарный объём исследуемого материала (с учетом содержания воды), м $^{3}$;

$f=f_{\text {рез }}$, МГц;

$E_{M}-$ амплитуда напряженности электромагнитного поля;

$\operatorname{tg} \delta$ - тангенс угла потерь;

$\varepsilon$ - относительная диэлектрическая проницаемость исследуемого материала.

Если считать, что вода не смешивается и не реагирует с другими компонентами исследуемого материала, и она равномерно распределена по всему объему образца, то $\varepsilon$ можно определить по формуле

$$
\varepsilon=\frac{\varepsilon_{C M} \times V_{C M}+\varepsilon_{B} \times V_{B}}{V},
$$

где $\varepsilon_{\mathrm{cm}}-$ относительная диэлектрическая проницаемость сухого материала;

$V_{\text {см }}$ - объём сухого материала, ${ }^{3}$; $\mathrm{M}^{3}$

$V_{B}$ - объём воды в исследуемом материале,

$\varepsilon_{\text {в }}$ - относительная диэлектрическая проницаемость воды.

Анализируя эти формулы, можно сделать вывод, что с ростом влажности материала происходит его нагрев, который фиксируется измерительными приборами (термометром, пирометром и т. п.).

Для подтверждения возможности использования предложенного метода, были проведены опыты.

При проведении опытов применялось следующие приборы и оборудование (рис. 6):

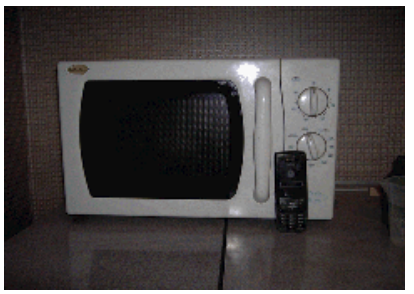

a)

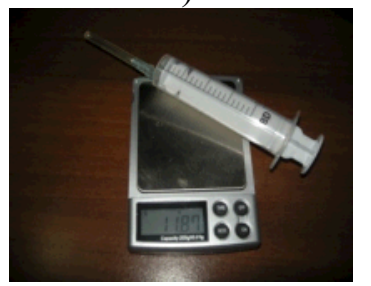

B)

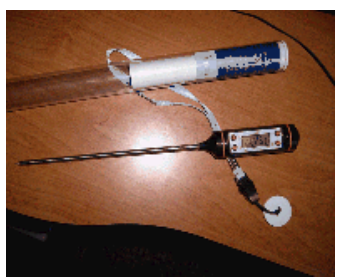

б)

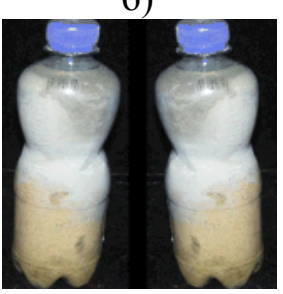

г)
Рисунок 6 - Приборы и оборудование, применяемые для определения влажности материала:

а) СВЧ излучатель; б) цифровой термометр;

в) шприц и электронные весы; г) образцы материала, подготовленные к испытанию

- СВЧ излучатель NN-GF574MZPE (Мощность 1000 Вт, Объем 27 л);

- цифровой ваттметр СМ3010 класса точности 0,1 , приведенная погрешность измерения тока и напряжения на переменном токе в диапазоне частот от 40 до 1500 Гц $\pm 0,1 \%$ (применялся для контроля потребляемой СВЧ излучателем мощности);

- весы электронные, с точностью 0,01 г;

- шприц, объемом до 20 мл;

- термометр цифровой электронный с металлическим щупом WT-1, диапазон измерения температуры от $-50{ }^{\circ} \mathrm{C}$ до $+300{ }^{\circ} \mathrm{C}$; дискретность $0,1{ }^{\circ} \mathrm{C}$; абсолютная погрешность $\pm 1{ }^{\circ} \mathrm{C}$ в диапазоне от $-20{ }^{\circ} \mathrm{C}$ до $+80{ }^{\circ} \mathrm{C}$ (использовался для измерения температуры внутри образца) (рис. 6); 
Одеська державна академія технічного регулювання та якості

- ёмкости для нагрева исследуемого материала из полиэтилентерефталата (ПЭТ), объемом 0,5 литров. Ёмкость, была оборудована герметично закручивающейся пробкой, которая предотвращала испарение жидкости из пробы материала при ее нагревании (рис. 6).

В качестве объекта исследования был принят мытый сухой кварцевый песок Вознесенского карьера с модулем крупности 2,5, массой 500 г.

Порядок проведения исследований.

1. В сушильный шкаф помещался исследуемый материал и нагревался до температуры $\mathrm{t}=200{ }^{\circ} \mathrm{C}$. После обезвоживания материал помещался в ёмкость для проведения испытания и герметично закрывался.

2. Затем ёмкость при достижении $20^{\circ} \mathrm{C}$ помещалась в СВЧ излучатель и подвергалась нагреву в течение 15 минут.

3. После этого с помощью цифрового термометра определялась температура внутри образца.

4. Затем в ёмкость с песком добавляли воду.

5. Опыты повторялись. Относительное количество добавляемой воды (Мв) к песку (Мп), определялась выражением: Мп/Мв. В исследованиях Мп / Мв составило: 50 (10 гр.), 20 (25 гр.), 10 (50 гр.), 7 (71 гр.), 5 (100 гр.), 4 (125 гр.).

6. Необходимое количество воды определялось с использованием электронных весов.

7. Образцы с водой подвергались воздействию СВЧ излучения в течение 15 минут с интервалом 1, 5, 7, 9, 12, 15 минут. Опыты проводились три раза для каждой точки эксперимента. Результат усреднялся.

Результаты представлены на рис. 7.

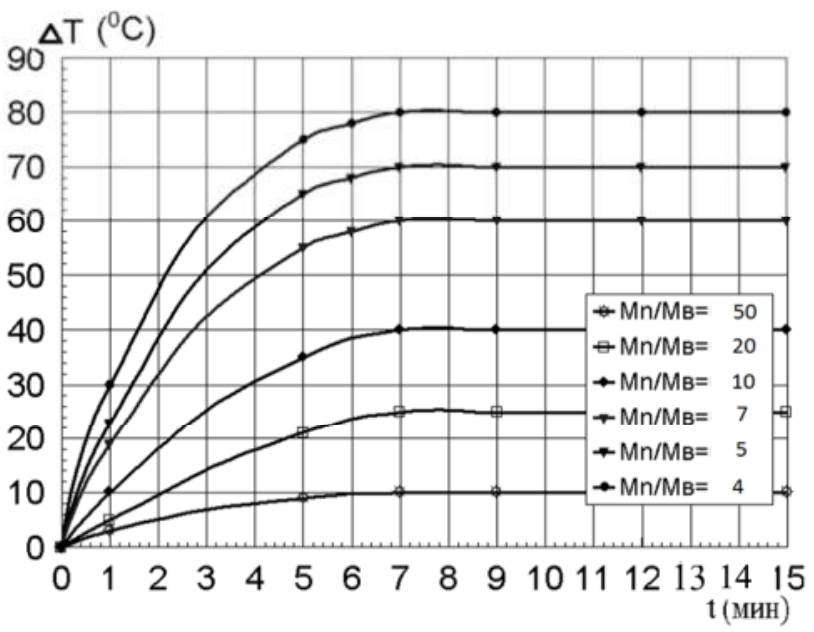

Рисунок 7 - Зависимость изменения температуры нагрева образца от времени воздействия СВЧ излучения (песок фр. 2,5)
Экспериментальные исследования показали, что наличие воды приводит к нагреву материала. $\mathrm{C}$ течением времени температура стабилизируется. Дальнейший нагрев не приводит к повышению температуры.

\section{Выводы}

Как показали исследования, предложенный метод может быть использован для определения количества воды в строительных материалах.

Нагрев исследуемых образцов, как показали опыты, зависит только от количества воды, времени и мощности воздействия СВЧ излучения. Поэтому это дает возможность, применять предложенный метод и для других строительных материалов, которые не реагируют на СВЧ излучения (щебень, цемент, и т.п.).

\section{Список использованных источников}

1. Крамаренко В. В. Применения СВЧметода для определения влажности песчаных грунтов / В. В. Крамаренко, А. Н. Никитенков, В. Ю. Молоков // Современные проблемы науки и образования. - 2015. - № 1-1.; [Электронный pecypc]. - Режим доступа: https://www.scienceeducation.ru/ru/article/view?id=18451 (дата обращения: 03.08.2017).

2. Технические указания по устройству дорожных оснований из обломочных материалов, укрепленных цементом / ВСН 164-69. - [Действующий от 1970-01-04]. - M, 1970. - 38 с.

3. Будников Д. А. Интенсификация сушки зерна активным вентилированием с использованием электромагнитного поля СВЧ: автореф. дис. ... канд. техн. наук: 05.20.02 / Д. А. Будников; АЧГАА. - Зерноград, 2008. - 21 с.

4. Солоненко И. П. Определение содержания влаги в образцах материалов для дорожного строительства / И. П. Солоненко, А. В. Леонова // Восьма Всеукраїнська науково-практична конференція молодих учених і студентів «Технічне регулювання, метрологія та якість: виклики сучасності» (Одеса, травень) ОДАТРЯ, м. Одеса: 2017. - C. $128-129$.

5. ASTM D 4643-08. Standard Test Method for Determination of Water (Moisture) Content of Soil by Microwave Oven Heating.

6. Miller, R. J. et al., «Soil water content microwave oven method». Soil Science Society of America Proceedings, Vol. 38, No. 3, 1974. - p. 535 $-537$.

7. Philip W. K. Chung and Tony Y. K. Ho, «Study on the determination of moisture content of soils by microwave oven method». Geo Report no. 221, Geotechnical Engineering Office, Hong Kong, 2008. 
8. Ryley, M. D., «The use of a microwave oven for the rapid determination of moisture content of soils». RLR Report LR280. Road Research Laboratory, Crowthorne, England, 1969.

9. Ломоносов Д. А. Повышение долговечности плунжерных пар дизельной топливной аппаратуры за счет контроля влагосодержания в топливной системе (в условиях эксплуатации юга Дальнего Востока): автореф. дис. ... канд. техн. наук: 05.20 .03 / Д. А. Ломоносов; ПГСА. M., 2006. $-18 \mathrm{c}$.

Поступила в редакичию 16.05.2016

Рецензент: д.т.н., проф. Братченко Г. Д., Одесская государственная академия технического регулирования и качества, г. Одесса.

\section{І. П. Солоненко, к.т.н.}

\section{ЗАСТОСУВАННЯ НВЧ ВИПРОМІНЮВАЧІВ ДЛЯ ВИЗНАЧЕННЯ ВМІСТУ ВОЛОГИ У ЗРАЗКАХ БУДІВЕЛЬНИХ МАТЕРІАЛІВ}

У статті розглядаються існуючі методи визначення вмісту вологи у будівельних матеріалах. Приводяться результати їх аналізу та порівняння. Запропоновано метод визначення кількості води, яка знаходиться у будівельних матеріалах, иляхом впливу на них надвисокочастотного випромінювання фіксованої потужності та часу впливу. Наведено методику його застосування в інженерній $i$ технологічній практиці.

Ключові слова: вологість, будівельні матеріали, НВЧ, пісок, вимірювання, зразок.

I. P. Solonenko, $\mathrm{PhD}$

\section{THE USE OF A MICROWAVE OVEN FOR DETERMINATION OF MOISTURE CONTENT IN SAMPLES OF BUILDING MATERIALS}

In this article the existing methods of moisture content determination in building materials are considered. The results of their analysis and comparison are presented. The method of determination of the amount of water in building materials through exposure to microwave emission with fixed power and exposure time is offered. The implementation of the method in engineering and technological practice is given herein.

Keywords: moisture content, building materials, microwave, sand, measurement, sample.

УДК 621.86

К. Ф. Боряк, д.т.н., А. Г. Цимбалюк, О. О. Лопатін

Одеська державна академія технічного регулювання та якості, м. Одеса

\section{ПІДВИЩЕННЯ ТОЧНОСТІ ВИМІРЮВАННЯ МАСИ КАЛІБРУВАЛЬНИМ ПРИСТРОЕМ ЗНКП-60}

В статті розглядаються результати виконаної науково-дослідної роботи з розробки нового зважувального неавтоматичного калібрувального пристрою для великовантажних платформних ваг з найбільшою границею зважування 60 т (ЗНКП-60), який для створення зусиль навантаження на вантажсопиймальну платформу використовує гідравлічні домкрати і баластний вантаж. Було розроблено декілька варіантів конструкиії ЗНКП-60, кожен з яких має свої переваги і обмеження щодо застосування на практиці. Авторами пропонуються заходи по вдосконаленню пристрою ЗНКП-60, які суттєво підвищують точність вимірювання маси і розширюють сферу його застосування.

Ключові слова: зважувальний неавтоматичний калібрувальний пристрій, вантажоприймальна платформа, вагопередавальний пристрій, залізничні ваги, безгирна повірка, калібрування великовантажних ваг, еталонні засоби вимірювання маси.

Актуальність досліджень існуючої проблеми. В даний час в Україні $є$ дефіцит вагоповірочних вагонів, що призводить до тривалої затримки у часі та зриву термінів міжповірочного інтервалу. Крім того, доставка вагоповірочного вагону до місця повірки і робота 3 ним вима- 